\title{
Barriers and facilitators for oncology nurses discussing sexual issues with men diagnosed with testicular cancer
}

\author{
Moore A, $\underline{\text { Higgins A, Sharek D. }}$ \\ Milford Care Centre, Plassey Road, Castletroy, Limerick, Ireland. Electronic address: \\ a.moore@milfordcarecentre.ie.
}

\section{INTRODUCTION}

Testicular cancer is the most common cancer in men aged 15-40 (Chia et al 2010) and it can strike at any age (Sanden et al. 2000; Brown 2003; Jemal et al. 2007), with approximately 168 new cases diagnosed in Ireland each year (National Cancer Registry of Ireland 2011). Testicular cancer assaults an organ associated with sexuality and reproduction and occurs in a period of life which is characterised by major social life changes and when sexual desire and performance, sense of masculinity, body image and fertility can be central issues (Moore and Higgins 2009; Jankowska 2012). Nurses, because of their ongoing contact with patients are in an ideal position to provide information, support and counselling in relation to sexuality. To date, no research has been conducted exploring how oncology nurses address sexuality concerns in men with testicular cancer. Therefore, this study aimed to address this gap by investigating oncology nurses' self-perceived knowledge and comfort in relation to discussing sexuality concerns with men diagnosed with testicular cancer and to identify the barriers and facilitators to such discussions. 


\section{BACKGROUND}

Testicular cancer treatments, such as surgery, chemotherapy and radiotherapy may damage reproductive organs and peripheral nerves resulting in reduced testosterone and libido, a ceasing of the production of semen, erection and ejaculatory difficulties, and impaired fertility or impotence (Rudberg et al. 2002; Fay 2003; Gurevich et al. 2004; Algier and Kav 2008; Moore and Higgins 2009; Rossen et al 2012). In addition, treatments may not only interfere with the anatomy and physiology of the sexual system, but they can also impacts on a person's sexual identity and body image (Gurevich et al. 2004; Robertson 2010; Moore and Higgins 2009). Research suggests that men with testicular cancer may feel less virile, less sexually attractive and have lower self-esteem, giving rise to reduced sexual interest, activity and enjoyment (Heidenreich and Hofmann 1999; Jonker-Pool et al, 2001 Reese 2011; Rossen et al 2012). For men that are concerned with physical appearance, the absence of a testis can lead to feelings of shame and cause a man to avoid certain activities, such as sport, which could lead to social isolation (Van Basten 1996), A diagnosis of testicular cancer and the subsequent treatment can also put a strain on relationships due to periods of hospitalisation, separation from partners, role change and financial difficulties all of which can lead or exacerbate relationship difficulties (Syse and Kravdal 2007).

Research, however, suggests that despite advances in the use of evidence based practice within nursing, there remains a sharp contrast between nurses' positive perceptions of their role and their actual practice in relation to sexuality. Studies involving nurses, working in areas other than with testicular cancer patients, have shown that nursing practice in sexuality counselling is 
inconsistent, with many nurses reporting that they did not always let patients know they were available to discuss sexual concerns and feel patients should initiate discussions around sexuality (Kautz et al. 1990; Gamel et al. 1995; Cort 1998; Guthrie 1999; Butler and Banfield 2001; Magnan et al 2005; Higgins et al. 2008). Personal feelings of embarrassment and discomfort when discussing sexual issues with patients is a possible cause for nurses' reluctance to engage in this area of practice (Gamel et al. 1995; Cort 1998; Guthrie 1999; Tsai 2004; Magnan et al 2005; Higgins et al. 2008). A further identified barrier was nurses' lack of knowledge regarding referral resources should a patient require further consultation (Kautz et al. 1990; Tsai 2004). Nurses also deemed hospital wards an unsuitable environment to discuss sexual concerns with patients (Guthrie 1999; Lemieux et al. 2004) and felt that work stress, lack of time, heavy workloads, shorter stays in hospital and multiple care providers all limited opportunities to address sexual concerns with patients (Butler and Banfield 2001; Lemieux et al. 2004; Tsai 2004). Furthermore, Tsai (2004) found management not to be supportive in the facilitation of addressing sexual concerns, with nurses reporting being told that sexuality is the least important aspect of nursing care.

Overall, these studies demonstrated that despite increased recognition of the impact of testicular cancer on patients' sexuality, sexuality may not be addressed by nurses during clinical encounters with patients. As there are no existing studies that specifically explore how oncology nurses address sexuality concerns in men with testicular cancer, this study aimed to address this research gap. 


\section{METHODS}

\section{Aim}

The aims of the study was to investigate oncology nurses self-perceived knowledge and comfort in relation to discussing sexuality concerns with men diagnosed with testicular cancer and to identify the barriers and facilitators to such discussions.

\section{Design}

This study employed a self-completion, anonymous survey design with a sample of registered nurses working in five, randomly chosen oncology centres in Ireland.

\section{Questionnaire}

A structured, self-administered questionnaire was devised by the researchers and informed by the nursing literature (Kautz et al. 1990; Waterhouse and Metcalfe 1991; Matocha and Waterhouse 1993; Gamel et al. 1995; Guthrie 1999; Lemieux et al. 2004; Tsai 2004). The final questionnaire consisted of 71 questions divided into four sections. Section one contained 12, closed-ended questions around demographics including age, gender, religion, current position, years of experience and previous education in the area of sexuality education. In addition, it sought to establish the frequency the nurses informed their patients they were available to discuss sexuality concerns or were asked by patients about their sexuality concerns. Section two included a number of sections that addressed perceived barriers to discussing sexuality issues under the following headings: knowledge (12 items), comfort (12 items), environment (6 items), patient variables ( 7 items) and other potential barriers (11 items). Section three included 10 items that might potentially facilitate discussion. All the questions in sections two 
and three were in the form of statements and required participants to rate responses on a five point Likert scale ranging from strongly agree to strongly disagree or from very comfortable to very uncomfortable. The final section had a comments section to allow participants to write in any additional comments on discussing sexuality with testicular cancer patients.

\section{Participants and sampling}

In the absence of a comprehensive database of registered nurses currently employed in oncology settings, this study drew from a convenience sample of nurses employed in five oncology settings which were randomly selected from 13 centres in Ireland. Two centres were located in a major city and three were regional centres. All registered staff nurses, clinical nurse managers, clinical nurse specialists and advanced nurse practitioners employed in these settings were eligible to participate. Of the 200 oncology nurses in the sampling frame who fulfilled the inclusion criteria, 105 returned the survey, representing a 53\% response rate. However, as 16 of these questionnaires had a significant amount of incomplete questions, only 89 questionnaires (45\% response rate) were included in the final analyses.

\section{Data collection}

A letter was sent to all the Directors of Nursing and hospital management in the selected centres requesting permission for access. To maintain anonymity, questionnaires were distributed in each hospital by an appointed gatekeeper who, in turn, sent a sealed envelope containing a letter explaining the study, the questionnaire and a stamped addressed return envelope to all potential participants. In order to increase the response rate, a reminder letter 
and questionnaire was forwarded to each participant two weeks later encouraging them to complete the questionnaire and thanking those who had already returned the questionnaire.

\section{Data analysis}

Statistical Package for Social Sciences (SPSS) version 17.0 was used for quantitative data analysis. Frequencies and descriptive statistics were calculated for each variable and a Mann Whitney U-test were used to examine statistically significant differences between those working as Clinical Nurse Specialist (CNS) and non clinical nurse specialists on the following variables: discussing sexual concerns, knowledge, comfort, environmental barriers, reactions barriers, and demographic barriers. The qualitative comments at the end of the questionnaire were analysed using content analysis through which comments were classified into major categories developed due to their theoretical importance (Burns and Grove 2001).

\section{Validity and reliability}

Content validity was determined with a panel of six experts consisting of three clinical nurse specialists in oncology, an oncology unit manager and two consultants (an oncologist and a radiation oncologist). Overall, the feedback received was positive. Some advice was given on layout, structure and question wording; adjustments were made accordingly. In order to examine the stability of the questionnaire over time, a pilot study was also conducted. The questionnaire was distributed to 40 general nurses from three surgical units who care for men 
pre and post surgery for testicular cancer. The response rate was $65 \%(n=26)$. Only minor changes were made following the pilot.

\section{Ethical considerations}

Ethical approval to undertake this study was sought and received prior to undertaking the study from the university ethics committee. The letter provided with the questionnaire stated that participation was completely voluntary and consent was assumed upon return of the questionnaire.

\section{FINDINGS}

\section{Demographics}

All of the participants were female and approximately half were between 31-40 years. Ninety percent were Roman Catholic. More than $43 \%$ were educated to Higher Diploma or Masters level. The length of time working in oncology was quite varied and just over half of the sample was at staff nurse grade. Table 1 provides further demographic details

Table 1. Demographics of sample

$$
\begin{aligned}
& \text { Variable } \\
& \text { ( } n=89 \text { ) } \\
& \text { Gender }
\end{aligned}
$$$$
\text { n (\%) }
$$$$
\text { Female }
$$$$
89(100.0)
$$ 


\begin{tabular}{|lc|}
\hline Male & $0(0.0)$ \\
Age in years & \\
$20-30$ & $30(33.7)$ \\
$31-40$ & $46(51.7)$ \\
$41-50$ & $9(10.1)$ \\
$51+$ & $4(4.5)$ \\
& \\
Religion & \\
Roman Catholic & \\
Church of Ireland & $81(91.0)$ \\
Methodist & $4(4.5)$ \\
Other & $1(1.1)$ \\
& $3(3.4)$ \\
Highest academic qualification & \\
Certificate in nursing or midwifery & \\
Diploma or bachelors degree in nursing & $13(14.6)$ \\
Higher diploma in oncology & $34(38.2)$ \\
Masters degree & $22(37.1)$ \\
Other & $6(6.7)$ \\
& $3(3.4)$ \\
Length of time working in oncology & \\
Less than 1 year & \\
1-5 years & $15(16.9)$ \\
6-10 years & $28(31.5)$ \\
More than 10 years & $27(30.3)$ \\
Current practice area & $19(21.3)$ \\
Oncology in patient & \\
Oncology day unit & \\
Oncology out patient & \\
Other & $48(53.9)$ \\
Current position & $24(27.0)$ \\
Ctaff nurse & $17(12.7)$ \\
Clinical Nurse Specialist & \\
\hline
\end{tabular}




\section{Sexuality education received}

Nearly $20 \%$ ( $n=16$ ) of the sample reported receiving no sexuality education in pre-registration programmes, with this figure rising to nearly $30 \%(n=26)$ for post-registration programmes. Approximately, one-third of the sample received between one to five hours of sexuality education content in both pre-registration $(n=27)$ and post-registration $(n=29)$ education. Just $3 \%$ and $6 \%$ received more than 10 hours of sexuality education in their pre-registration or post registration programmes, respectively

\section{Current clinical practices}

Just $10 \%(n=9)$ of participants frequently or very frequently informed patients they were available to discuss their sexual concerns. Just over half (51\%) informed patients occasionally, with more than one-third (39\%) reporting that they never informed patients. Half of the sample (50\%) reported that none of their patients had asked to discuss their sexual concerns, with $40 \%$ reporting that one to five of their patients had asked. Just one participant had discussed sexual concerns with more than 10 patients.

\section{Participants reported knowledge levels on sexuality and testicular cancer}

Participants' self reported knowledge levels on 12 different areas related to sexuality and testicular cancer were examined. No more than $70 \%$ of the sample felt they had sufficient knowledge to discuss any of the 12 topics identified. Between $57 \%$ and $70 \%$ of the sample reported feeling they had sufficient knowledge to respond to a patient's misinterpretation of 
questions (69\%) and to discuss the option of sperm banking (67\%), fertility concerns (60\%), and the impact of cancer and its treatment on the patient's sexual function (57\%). On the other hand, between $50 \%$ and $60 \%$ of participants did not feel they had the sufficient knowledge to talk to patients about the option of prosthesis (60\%), the impact of impotence (50\%), ejaculatory difficulties (57\%) and erectile dysfunction (55\%). In addition, 45\% reported lacking sufficient knowledge to talk to patients about testicular self examination (See Table 2). The qualitative comments written by participants also supported lack of knowledge in particular areas. One participant summarised quite clearly her issues with discussing specific sexual topics with her patients: "I feel capable of discussing some of these matters with patients however, relating to specific male difficulties, i.e. erectile problem, impotence and prosthesis, I don't have enough specific knowledge."

Table 2.Participants self-reported knowledge levels on sexuality and testicular cancer

\begin{tabular}{|lccc|}
\hline $\begin{array}{l}\text { I have the knowledge to talk to } \\
\text { patients about... } \\
(\mathbf{n}=\mathbf{8 8})\end{array}$ & $\begin{array}{c}\text { Agree or strongly } \\
\text { agree } \\
\mathbf{n}(\mathbf{\%})\end{array}$ & $\begin{array}{c}\text { Neutral } \\
\mathbf{n}(\%)\end{array}$ & $\begin{array}{c}\text { Disagree or } \\
\text { strongly disagree } \\
\mathbf{n}(\%)\end{array}$ \\
\hline $\begin{array}{l}\text { misinterpretations of the intentions } \\
\text { of my questions. }\end{array}$ & $\mathbf{6 1 ( 6 9 . 3 )}$ & $13(14.8)$ & $14(15.9)$ \\
\hline the option of sperm banking. & $\mathbf{5 9 ( 6 7 . 0 )}$ & $9(10.2)$ & $20(22.7)$ \\
\hline their concerns regarding fertility. & $\mathbf{5 3 ( 6 0 . 2 )}$ & $11(12.5)$ & $24(27.3)$ \\
\hline $\begin{array}{l}\text { the impact of cancer/treatment on } \\
\text { the patient's male sexual function. }\end{array}$ & $\mathbf{5 0 ~ ( 5 6 . 8 )}$ & $8(9.1)$ & $34(34.1)$ \\
\hline $\begin{array}{l}\text { their concerns to talking to their } \\
\text { partner about sexual function. }\end{array}$ & $41(46.5)$ & $13(14.8)$ & $37(42.1)$ \\
\hline $\begin{array}{l}\text { their concerns regarding future } \\
\text { sexual relationships. }\end{array}$ & $39(44.3)$ & $12(13.6)$ & $37(42.1)$ \\
\hline $\begin{array}{l}\text { the impact of an orchidectomy } \\
\text { (removal of testes) on the patient's } \\
\text { body image. }\end{array}$ & $37(42.1)$ & $14(15.9)$ & $\mathbf{4 0}(\mathbf{4 5 . 5 )}$ \\
\hline $\begin{array}{l}\text { how to carry out a testicular self } \\
\text { examination. }\end{array}$ & $40(45.4)$ & $8(9.1)$ & \\
\hline
\end{tabular}




\begin{tabular}{|llll|}
\hline the impact of impotence. & $31(35.2)$ & $13(14.8)$ & $\mathbf{4 4}(\mathbf{5 0 . 0 )}$ \\
\hline $\begin{array}{l}\text { the impact of an erectile } \\
\text { dysfunction. }\end{array}$ & $26(29.5)$ & $14(15.9)$ & $\mathbf{4 8 ( 5 4 . 6 )}$ \\
\hline the option of prosthesis. & $20(22.7)$ & $15(17.0)$ & $\mathbf{5 3 ( 6 0 . 3 )}$ \\
\hline ejaculatory difficulties. & $20(22.7)$ & $18(20.5)$ & $\mathbf{5 0}(\mathbf{5 6 . 8})$ \\
\hline
\end{tabular}

\section{Participants comfort levels in discussing aspect of sexuality and testicular cancer}

Participants comfort levels on 12 different areas related to sexuality and testicular cancer were also examined (see Table 3). Over $50 \%$ of participants felt comfortable or very comfortable discussing the option of sperm banking (71\%), fertility concerns (67\%), responding to a patient's misinterpretation of questions (54\%) and discussing the impact of cancer and its treatment on the patient's sexual function (51\%). Between $42 \%$ and $52 \%$ of participants, however, felt uncomfortable or very uncomfortable discussing the option of prosthesis (42\%), the impact of impotence (47\%), ejaculatory difficulties (53\%) erectile dysfunction (52\%) with patients.

A significant number (39\%) also reported being uncomfortable talking to patients about testicular self examination. Participants' qualitative comments also supported this lack of comfort with a number stressing the importance of education in enhancing knowledge and comfort levels: "Workshops and a more open atmosphere surrounding discussing sexuality would encourage me personally to bring it up in conversation. Being knowledgeable about the topic would make me feel more comfortable and able to discuss it confidently." 
Table 3.Participants self-reported comfort levels in talking to patients about sexuality and testicular cancer

\begin{tabular}{|c|c|c|c|}
\hline $\begin{array}{l}\text { I am comfortable talking to } \\
\text { patients about... } \\
\text { (n= 89) }\end{array}$ & $\begin{array}{l}\text { Comfortable or } \\
\text { very comfortable } \\
n(\%)\end{array}$ & $\begin{array}{l}\text { Neutral } \\
\text { n (\%) }\end{array}$ & $\begin{array}{c}\text { Uncomfortable } \\
\text { or very } \\
\text { uncomfortable } \\
n(\%)\end{array}$ \\
\hline the option of sperm banking. & $63(70.8)$ & $10(11.2)$ & $16(18.0)$ \\
\hline their concerns regarding fertility. & $60(67.4)$ & $13(14.6)$ & $16(18.0)$ \\
\hline $\begin{array}{l}\text { responding to a patient who } \\
\text { misinterprets the intentions of my } \\
\text { questions. }\end{array}$ & $48(53.9)$ & $17(19.1)$ & $24(27.0)$ \\
\hline $\begin{array}{l}\text { the impact of cancer/treatment on } \\
\text { the patient's male sexual function. }\end{array}$ & $45(50.6)$ & $14(15.7)$ & $30(33.7)$ \\
\hline $\begin{array}{l}\text { their concerns regarding future } \\
\text { sexual relationships. }\end{array}$ & $42(47.2)$ & 15 (16.9) & 32 (35.9) \\
\hline $\begin{array}{l}\text { their concerns to talking to their } \\
\text { partner about sexual function. }\end{array}$ & $40(45.0)$ & $20(22.5)$ & $29(32.5)$ \\
\hline $\begin{array}{l}\text { the impact of an orchidectomy } \\
\text { (removal of testes) on the patient's } \\
\text { body image. }\end{array}$ & $36(40.4)$ & $20(22.5)$ & $33(37.1)$ \\
\hline $\begin{array}{l}\text { how to carry out a testicular self } \\
\text { examination. }\end{array}$ & $36(40.5)$ & $18(20.2)$ & $35(39.3)$ \\
\hline the option of prosthesis. & $32(35.9)$ & $20(22.5)$ & $37(41.6)$ \\
\hline the impact of impotence. & $31(34.8)$ & $16(18.0)$ & $42(47.2)$ \\
\hline ejaculatory difficulties. & $26(29.2)$ & $16(18.0)$ & $47(52.8)$ \\
\hline $\begin{array}{l}\text { the impact of an erectile } \\
\text { dysfunction. }\end{array}$ & $25(28.1)$ & $18(20.2)$ & $46(51.7)$ \\
\hline
\end{tabular}

\section{Participants views on environmental barriers to discussing sexual concerns}

Participants were asked about six environmental factors that may be barriers to discussing patients' sexual concerns (see Table 4). The majority of participants agreed or strongly agreed that three of the factors served as barriers to discussing patients' sexual concerns: lack of a private environment (64\%), lack of services to refer patients (58\%) and a heavy workload resulting in lack of time (49\%). Over $50 \%$ of the sample disagreed that the following three factors were barriers: short duration of a patient's stay (59\%), sexual concerns are too private 
to document (53\%) and a lack of support from colleagues or managers (56\%). Although a lack of support from managers and colleagues was not one of the primary environmental barriers found in the quantitative aspect of the survey, a significant minority (18\%) of the sample in the qualitative comments were of the view that a lack of support from managers and colleagues was a barrier, as described by this participant: "I feel it is not encouraged to bring up or talk about sexual issues. I have not previously encountered this on other units and feel it may be to the unit where I work. This needs to be changed from the top down."

Table 4.Participants self-reported barriers to discussing patients' sexual concerns

\begin{tabular}{|c|c|c|c|}
\hline $\begin{array}{l}\text { I do not talk to patients about their } \\
\text { sexual concerns because... } \\
(n=88)\end{array}$ & $\begin{array}{c}\text { Agree or } \\
\text { strongly agree } \\
\mathrm{n}(\%)\end{array}$ & $\begin{array}{l}\text { Neutral } \\
\text { n (\%) }\end{array}$ & $\begin{array}{c}\text { Disagree or } \\
\text { strongly disagree } \\
\mathbf{n}(\%)\end{array}$ \\
\hline lack of private environment. & $56(63.6)$ & $5(5.7)$ & $27(30.7)$ \\
\hline $\begin{array}{l}\text { lack of services to refer to } \\
\text { patients. }\end{array}$ & $51(58.0)$ & $14(15.9)$ & $23(26.1)$ \\
\hline $\begin{array}{l}\text { heavy workload resulting in lack } \\
\text { of time. }\end{array}$ & $43(48.9)$ & $15(17.0)$ & $30(34.1)$ \\
\hline $\begin{array}{l}\text { patients are only in the hospital } \\
\text { for a short period so there is no } \\
\text { time to discuss sexual issues. }\end{array}$ & $23(26.1)$ & $13(14.8)$ & $52(59.1)$ \\
\hline $\begin{array}{l}\text { patients' sexual concerns are too } \\
\text { private to document in the nursing } \\
\text { kardex. }\end{array}$ & $23(26.1)$ & $18(20.5)$ & $47(53.4)$ \\
\hline $\begin{array}{l}\text { lack of support from colleagues or } \\
\text { managers }\end{array}$ & $16(18.2)$ & $23(26.1)$ & $49(55.7)$ \\
\hline
\end{tabular}




\section{Participants views on patient variables as barriers to discussing sexual concerns}

Participants were asked about seven specific patient variables that could potentially be perceived as barriers to discussing a patient's sexual concerns. Most strongly, $46 \%$ of the sample felt they would be reluctant to have a discussion about sexual concerns with a patient with a mental health problem. While between $20 \%$ and $30 \%$ of participants felt that if a patient were of a different culture (29\%), religion (27\%), age group (23\%) or gender (21\%) it might present a barrier, approximately $40 \%$ to $60 \%$ disagreed that these were barriers. Participants disagreed most strongly (61\%) that a patient being single would cause them to be reluctant to discuss sexuality concerns. Qualitative comments revealed that the sample had difficulties addressing issues with people from different cultures, with one nurse writing: "I found language and religion a barrier when dealing with patients from different cultures."

Table 5. Participants views on patient related variables that would impact on their willingness to discuss patients sexual concerns

\begin{tabular}{|c|c|c|c|}
\hline $\begin{array}{l}\text { I would be reluctant to... } \\
\text { ( } n=89)\end{array}$ & $\begin{array}{c}\text { Agree or strongly } \\
\text { agree } \\
\text { n (\%) }\end{array}$ & $\begin{array}{l}\text { Neutral } \\
\text { n (\%) }\end{array}$ & $\begin{array}{c}\text { Disagree or } \\
\text { strongly disagree } \\
\mathbf{n}(\%)\end{array}$ \\
\hline $\begin{array}{l}\text { to raise a discussion about the } \\
\text { impact of testicular cancer on their } \\
\text { sexuality with a patient who I knew } \\
\text { had a mental health problem. }\end{array}$ & $41(46.1)$ & $24(27.0)$ & $24(27.0)$ \\
\hline $\begin{array}{l}\text { to raise a discussion about the } \\
\text { impact of testicular cancer on their } \\
\text { sexuality with a patient who is of a } \\
\text { different culture. }\end{array}$ & $26(29.2)$ & $28(31.5)$ & 35 (39.3) \\
\hline $\begin{array}{l}\text { raise a discussion about the impact } \\
\text { of testicular cancer on their } \\
\text { sexuality with a patient who is of a } \\
\text { different religion. }\end{array}$ & 24 (26.9) & $28(31.5)$ & 37 (41.6) \\
\hline
\end{tabular}




\begin{tabular}{|llll|}
\hline $\begin{array}{l}\text { talk to a patient younger than me } \\
\text { about the impact of testicular } \\
\text { cancer on their sexuality. }\end{array}$ & $20(22.5)$ & $16(18.0)$ & $\mathbf{5 3}(\mathbf{5 9 . 5 )}$ \\
\hline $\begin{array}{l}\text { talk to a patient older than me } \\
\text { about the impact of testicular } \\
\text { cancer on their sexuality. }\end{array}$ & $20(22.5)$ & $14(15.7)$ & $\mathbf{5 5 ( 6 1 . 8 )}$ \\
\hline $\begin{array}{l}\text { talk to patients of the opposite } \\
\text { gender about the impact of } \\
\text { testicular cancer on their sexuality. }\end{array}$ & $19(21.4)$ & $22(24.7)$ & $\mathbf{4 8 ( 5 3 . 9 )}$ \\
\hline $\begin{array}{l}\text { talk to a patient about the impact } \\
\text { of testicular cancer on their } \\
\text { sexuality if they were single. }\end{array}$ & $16(18.0)$ & $19(21.3)$ & $\mathbf{5 4}(\mathbf{6 0 . 7 )}$ \\
\hline
\end{tabular}

\section{Other variables as barriers to discussing sexual concerns}

The survey also asked participants about a series of 11 other potential barriers related to the patient or others (see Table 6). There were relatively high percentages of participants who did not agree that patients might view discussing sexuality as the Clinical Nurse Specialist's (54\%) or doctor's (75\%) role; that patients might refuse to answer (63\%), not be interested (67\%), or might misinterpret (74\%) questions; and that colleagues might see sexuality discussion as infringing on patient's privacy (78\%). Participants were approximately evenly split about whether they felt patients prefer for nurses to wait until they raise their concerns and about whether a patient might get embarrassed if a nurse raises the discussion. Most strongly, nearly three-quarters (73\%) agreed or strongly agreed that patients might get embarrassed or offended if the nurse initiated a conversation about the impact of cancer on their sexuality if a family member of relative were present. Qualitatively, comments also supported participants concerns with talking to patients when a partner is present: "On a number of occasions, I have raised the issue of sexuality with patients where their partners were present. I felt that on some 
of these occasions their partners became embarrassed and did not want to talk about these

issues. Maybe this was because it was not a subject which has been brought up before."

Table 6. Participants self-reported perceptions of patient or other related barriers to discussing sexuality and testicular cancer

\begin{tabular}{|c|c|c|c|}
\hline $\begin{array}{l}\text { I would be reluctant to discuss sexuality and } \\
\text { testicular cancer because... }\end{array}$ & $\begin{array}{c}\text { Agree or } \\
\text { strongly agree } \\
\mathrm{n}(\%)\end{array}$ & $\begin{array}{c}\text { Neutral } \\
\mathrm{n}(\%)\end{array}$ & $\begin{array}{l}\text { Disagree or } \\
\text { strongly } \\
\text { disagree } \\
\mathrm{n}(\%)\end{array}$ \\
\hline $\begin{array}{l}\text { Patients would get embarrassed / offended } \\
\text { if I initiated a conversation about the impact } \\
\text { of cancer on their sexuality if a family } \\
\text { member or relative were present. }(n=89)\end{array}$ & 65 (73.1) & 10 (11.2) & $14(15.7)$ \\
\hline $\begin{array}{l}\text { Patients prefer nurses to wait until they } \\
\text { raise their concerns. }(n=89)\end{array}$ & 34 (38.2) & $26(29.2)$ & $29(32.6)$ \\
\hline $\begin{array}{l}\text { Patients would get embarrassed / offended } \\
\text { if I initiated a conversation about the impact } \\
\text { of cancer on their sexuality. }(n=89)\end{array}$ & $34(38.2)$ & $21(23.6)$ & $34(38.2)$ \\
\hline $\begin{array}{l}\text { Talking to patients about impact of cancer } \\
\text { on sexuality is the role of the Clinical Nurse } \\
\text { Specialist. }(n=89)\end{array}$ & $29(32.5)$ & $12(13.5)$ & $48(54.0)$ \\
\hline $\begin{array}{l}\text { Patient would get emotionally distressed if I } \\
\text { initiated a conversation about impact of } \\
\text { cancer on their sexuality. }(n=89)\end{array}$ & $20(22.5)$ & $20(22.5)$ & $49(55.0)$ \\
\hline $\begin{array}{l}\text { Patients do not want to talk about sexual } \\
\text { issues, as it is the furthest thing from their } \\
\text { minds when they have just been diagnosed } \\
\text { with testicular cancer. }(n=89)\end{array}$ & 16 (18.0) & 13 (14.6) & $60(67.4)$ \\
\hline $\begin{array}{l}\text { The patient's family/significant others would } \\
\text { not want nurses to talk to patients about } \\
\text { their sexual concerns. }(n=89)\end{array}$ & $11(12.4)$ & $19(21.3)$ & $59(66.3)$ \\
\hline $\begin{array}{l}\text { Patients do not want to talk to nurses about } \\
\text { sexual concerns as they consider it the } \\
\text { doctor's role. }(n=88)\end{array}$ & $9(10.2)$ & $13(14.8)$ & $66(75.0)$ \\
\hline $\begin{array}{l}\text { Other colleagues would think I was } \\
\text { infringing on the patient's right to privacy if I } \\
\text { raised a discussion on sexual issues. }(n=89)\end{array}$ & $9(10.1)$ & 11 (12.4) & $69(77.5)$ \\
\hline
\end{tabular}




$\begin{aligned} & \text { Patients might misinterpret my questions as } \\ & \text { a sexual advance or a seductive gesture. }(\mathrm{n}=\end{aligned}$
$\begin{aligned} & \text { 89) } \\ & \text { Patients would refuse to answer my }\end{aligned}$
$\begin{aligned} & \text { questions if I asked them about their worries } \\ & \text { about the impact of the cancer on their }\end{aligned}$

\section{Facilitators to discussing patients' sexual concerns}

Participants were asked about 10 factors that might facilitate discussions with patients about their sexual concerns (see Table 7). Across all 10 factors, more than $70 \%$ of the sample agreed that the factors identified would facilitate them in having discussions with patients about their sexual concerns and no more than $10 \%$ of the sample disagreed on any one factor. More than $90 \%$ of the sample agreed that the following factors would act as facilitators for engaging in discussions with patients about the impact of testicular cancer on sexuality: being asked questions by the patient regarding their sexuality (98\%), having knowledge on sexual difficulties testicular cancer patients experience $(92 \%)$, having a private environment on the ward to discuss sexual concerns (92\%), having sufficient time to sit and talk to patients (92\%) and being told by another professional that the patient had sexual concerns (91\%). 
Table 7. Participants' self-reported facilitators to discussing patients' sexual concerns

\begin{tabular}{|c|c|c|c|}
\hline $\begin{array}{l}\text { The following would facilitate me to talk to } \\
\text { patients about their sexual concerns... }\end{array}$ & $\begin{array}{c}\text { Agree or } \\
\text { strongly agree } \\
\mathrm{n}(\%)\end{array}$ & $\begin{array}{l}\text { Neutral } \\
\mathrm{n}(\%)\end{array}$ & $\begin{array}{l}\text { Disagree or } \\
\text { strongly } \\
\text { disagree } \\
\mathrm{n}(\%)\end{array}$ \\
\hline $\begin{array}{l}\text { being asked questions by the patient } \\
\text { regarding their sexuality. }(n=89)\end{array}$ & $87(97.8)$ & $1(1.1)$ & $1(1.1)$ \\
\hline $\begin{array}{l}\text { having knowledge on the sexual difficulties } \\
\text { testicular cancer patients experience. }(n=89)\end{array}$ & $82(92.1)$ & $4(4.5)$ & $3(3.4)$ \\
\hline $\begin{array}{l}\text { having a private environment on the ward to } \\
\text { discuss sexual concerns. }(n=89)\end{array}$ & $82(92.1)$ & $6(6.7)$ & $1(1.1)$ \\
\hline $\begin{array}{l}\text { having sufficient time to sit and talk to } \\
\text { patients. }(n=89)\end{array}$ & $82(92.1)$ & $6(6.7)$ & $1(1.1)$ \\
\hline $\begin{array}{l}\text { being told by another professional that the } \\
\text { patient had concerns. }(n=89)\end{array}$ & $81(91.0)$ & $3(3.4)$ & $5(5.6)$ \\
\hline $\begin{array}{l}\text { having received communication workshops } \\
\text { that involved role play which would help to } \\
\text { develop skills. }(n=89)\end{array}$ & $77(86.5)$ & $7(7.9)$ & $5(5.6)$ \\
\hline $\begin{array}{l}\text { having clinical policies on how to address } \\
\text { sexual issues. }(n=89)\end{array}$ & $69(77.5)$ & $13(14.6)$ & 7 (7.9) \\
\hline $\begin{array}{l}\text { to have known the patient for } 2-3 \text { weeks and } \\
\text { have developed a good rapport. }(n=89)\end{array}$ & $67(75.3)$ & $14(15.7)$ & $8(9.0)$ \\
\hline $\begin{array}{l}\text { having observed the CNS talking to patients } \\
\text { about sexual issues. }(n=88)\end{array}$ & $63(71.6)$ & $16(18.2)$ & $9(10.2)$ \\
\hline $\begin{array}{l}\text { being prompted in the nursing care plan. ( } n= \\
\text { 89) }\end{array}$ & $62(69.7)$ & $19(21.3)$ & $8(9.0)$ \\
\hline
\end{tabular}

\section{Relationship between clinical position and variables}

Statistically significant relationships were found between position working (CNS or non-CNS) on all of the scales tested (See table 8). CNS participants were significantly more likely $(M=2.5, S D$ $=1.05)$ to discuss sexual concerns with patients than non-CNS participants $(M=1.66, S D=.64)$. In terms of knowledge and comfort, CNS participants felt significantly more knowledgeable (M $=3.58, \mathrm{SD}=.84)$ and comfortable $(\mathrm{M}=3.50, \mathrm{SD}=.59)$ discussing sexual concerns than non-CNS participants (knowledge: $\mathrm{M}=2.90, \mathrm{SD}=.88$; comfort: $\mathrm{M}=2.99, \mathrm{SD}=.84)$. CNS $(\mathrm{M}=2.6078$ ) participants were also significantly less likely than non-CNS participants $(M=3.09, S D=.74)$ to 
feel that the environmental barriers presented were a factor in them discussing sexual concerns with patients. Similarly, CNS participants $(M=2.27, S D=.54)$ were significantly less likely than non-CNS participants $(M=2.73, S D=.65)$ to feel that reactions from others affected them discussing sexual concerns with patients.

Table 8 Relationship between position (CNS versus Non CNS) and variables

\begin{tabular}{|l|l|l|l|l|l|}
\hline $\begin{array}{c}\text { Willingness to } \\
\text { discuss sexual } \\
\text { concerns }\end{array}$ & \multicolumn{1}{|c|}{ Knowledge } & Comfort & Environmental & Patient related & Other variables \\
\hline $\mathrm{U}=304.0$ & $\mathrm{U}=338.0$ & $\mathrm{U}=408.5$ & $\mathrm{U}=403.5$ & $\mathrm{U}=333.5$ & $\mathrm{U}=349.5$ \\
$\mathrm{p}=.001^{* *}$ & $\mathrm{p}=.005^{* *}$ & $\mathrm{p}=.033^{* *}$ & $\mathrm{p}=.034^{* *}$ & $\mathrm{p}=.004 * *$ & $\mathrm{p}=.006^{* *}$ \\
\hline
\end{tabular}

**Statistically significant at the $.05 \alpha$ level

\section{DISCUSSION}

A diagnosis of testicular cancer may dramatically impact on a person's intimate and sexual world, and men require quality information and support to enable them to deal with the consequences. Despite the fact that the World Health Organisation first identified, in 1975, the need for health professionals to be educated in the area of sexuality, and over the years authors in areas other than nursing in testicular cancer have identified the need for nurses to provide sexual health advice to people in their care, this study suggests that little progress has been made in this area of practice. Although the nurses in the current study were open to addressing concerns with patients and reporting receiving education in the area of sexuality, less than $11 \%$ frequently or very frequently informed patients they were available to discuss their sexual concerns and a high percentage reported a lack of knowledge and discomfort in 
discussion issues, such as ejaculatory difficulties, erectile dysfunction, impotence, prosthesis options and testicular self examination. Other factors that inhibited nurses discussing issues included a perception that patients would prefer nurses to wait until they raised their sexuality concerns and a perception that patients would become embarrassed if a family member or relative were present during discussions, which has also been reported in other studies (Gamel et al. 1995; Cort 1998; Madan et al 2005; Higgins et al. 2008). In Madan et al (2005) study $73.3 \%$ beleived that patients did not expect nurses to discuss sexual concerns and thought sexuality should be discussed only if initiated by patients. This passive waiting stance, which puts the onus on the patient to raise issues for discussion, appears to ignore the findings from patient studies, where they assert that because of embarrassment nurses should take the first step and initiate discussions with them (Young 1984; Waterhouse and Metcalfe 1991; Dilloway and Hildyard 1998).

Similar to other studies, the major environmental barriers identified to discussing sexuality with patients was a lack of privacy, a lack of referral services and heavy workload leading to lack of time, factors which also featured strongly in other studies and may be simply a projection of personal discomfort (Butler and Banfield 2001; Lemieux et al. 2004; Tsai 2004). In comparison to other studies, only a small percentage of nurses reported that talking to patients of a different age, religion and culture would be a barrier. However, a high percentage reported concerns around discussing sexuality with people who had a mental health problem, a variable not explored in previous studies. While this concern is understandable given the research which indicates that general medical nurses feel 
unprepared and lack the competence to support and respond to people's with mental health problems (Reed and Fitzgerald 2005; Ross and Goldner 2009), it is worrying that the patients who may find it more challenging to raise sexual concerns (Higgins, 2008) and who may be at increased risk of a reoccurrence or worsening of their depression or anxiety are the least likely to receive the support and information required. Men who are un-partnered at the time of diagnosis may also be a particular vulnerable group as research indicate that they have significant worry about impact on the cancer on future relationships (Carpentier and Fortenberry, 2010). In addition, in view of Allanne and Russo's (2012) recent American study which suggest that suicide is more common in male patients with testis cancer than in the general population, and our knowledge of the impact of testicular cancer on men's personal sexual landscape, sense of self and psychological wellbeing it is imperative that oncology nurses engage with patients and their partners and discuss issues of sexuality in a more proactive and holistic manner. While the vast majority of patients will only require information, reassurance and permission to discuss their concerns and fears, some patients may require referral to psychosexual or other forms of therapy. The lack of referral services for specialist care is a concern as all oncology teams need a network of specialists to help with patients' sexual issues as part of post treatment sexual rehabilitation (McKee and Schover 2001), and this is an area that requires urgent attention within Irish oncology services.

Although not a major barrier the lack of support from colleagues and managers was identified both in the quantitative and qualitative data. In the absence of such support, there is a risk that sexuality is not considered an essential aspect of the nursing assessment (Kautz et al. 
1990; Tsai 2004), that nurses do not raise issues for discussion with the patient or other team members for fear of being perceived as 'deviant' and transgressing the norms of everyday practice (Higgins, 2012). The lack of support from managers may also prevents nurses from asking for help or guidance on issues of sexuality for fear of exposing their lack of knowledge and skill, leading to a continuous cycle that maintains both conscious and unconscious 'incompetence' in this area of practice.

In conclusion, findings from this study clearly indicate that there is an urgent need to enhance the availability and quality of sexuality education specifically tailored to oncology nurses in relation to testicular cancer. Future education programmes need to enable nurses develop the communication competencies to discuss the more intimate aspects of sexuality, such as sexual dysfunction, prosthesis options and testicular self examination. Nurse educators also need to provide practitioners with opportunities to practise raising and talking about sexual issues in 'safe simulated role play context', strategies that have been found useful in other contexts (Higgins 2011). Given nurses concerns around talking to patients who have experienced mental health issues, there is an urgent need to address this within curricula. In addition, nurses need to develop skills to explore and discuss issues with family members and partners as they may have specific questions or fears they want discussed (Higgins et al. 2006). In addition, given the absence of effective role modelling in practice, opportunities also need to be provided for staff to learn from role models, such as clinical nurse specialists, who have developed comfort and competence to discuss sexual issues. 
Sexuality must also be subsumed as an essential aspect of oncology nurses role through changes in clinical policies and nursing plans. In western societies, the discourse around sexuality is one that frequently has emphasised silence, shame and embarrassment, and a repressive multidisciplinary team culture can reinforce this silence and invisibility. Therefore, a culture within the team needs to be created where sexuality issues can be discussed and shared in an open yet confidential manner in the interests of all concerned. To do this, educators need to move beyond their traditional focus on the individual clinician and unidisciplinary education and develop, deliver and evaluate more interdisciplinary education programmes in this area (Higgins et al 2011).

\section{Limitations}

Although no other studies were located that discussed oncology nurses comfort or competence in dealing with sexual issues following a diagnosis and treatment for testicular cancer and the results of this study provide some valid and useful information, it has several limitations which must be considered. First, the results are non-generalisable in that the sample is relatively small and does not statistically reflect all nurses working in oncology in Ireland. Specifically, the sample was entirely female, the vast majority were Roman Catholic and half were staff nurses. Second, as participants self-selected to complete the questionnaire, it cannot be determined how those nurses who did not choose to participate might have responded. Third, although tests of reliability and validity were carried out on the questionnaire, it requires further testing to ensure its validity as there was no criteria 
available with which to compare it. It is also recommended that a further study be carried out with a larger, randomised and more representative sample.

\section{CONCLUSIONS}

The overall conclusion of the current study is that little has changes over the years and barriers still exist which prevent nurses from addressing sexuality concerns with patients. Many of the issues relate to lack of knowledge and comfort around the intimate aspects of sexuality, and factors such as lack of privacy, heavy workload and lack of time, aspects in which nurses have little control. However, personal discomfort and lack of knowledge can be improved upon and are achievable through education and role modelling. Not only would this be beneficial in helping nurses feel more comfortable and confident in addressing patients concerns, it may also prompt them to take the initiative and began discussions with patients. Unless nurses are willing to introduce the topic with patients diagnosed with testicular cancer, they will be unable to assess if patents have specific education and support needs in this area and may omit a vital facet to holistic nursing care for the person.

Acknowledgements: None

Conflict of interest: The authors have no conflicts of interest to disclose.

Funding sources: The authors have no funding sources to disclose. 


\section{REFERENCES}

Algier L. and Kav S. (2008) Nurses' approach to sexuality-related issues in patients receiving cancer treatments. Turkish Journal of Cancer 38(3), 135-141.

Blackmore C. (1989) Altered images. Nursing Times 22(85), 36-39.

Brown C.G. (2003) Testicular cancer: An overview. Medsurg Nursing 12(1), 37-43.

Burns N. and Grove S. (2001) Understanding Nursing Research. 3rd edn. W.B. Saunders Company, Philadelphia.

Butler L. and Banfield V. (2001) Oncology nurses' views on the provision of sexual health in cancer care. Journal of Sexology Reproduction Medicine 1(1), 35-39.

Carpentier, My; Fortenberry, J (2010) Romantic and sexual relationships, body image and fertility in adolescents and young adult testicular cancer survivors: a review of the literature. Journal of Adolescent Health 47 (2) 115-125.

Cort E. (1998) Nurses' attitudes to sexuality in caring for cancer patients. Nursing Times 94(42), $54-56$.

Dilloway M. and Hildyard S. (1998) Female patients' views on discussing sexual health. British Journal of Community Nursing 3(4), 172-177.

Fay A. (2003) Sexuality and the cancer patient. The Canadian Journal of Medical Radiation Technology 43(4), 12-14.

Gamel C., Hengeveld M., Davis B. and Van Der Tweel I. (1995) Factors that influence the provision of sexual health care by Dutch cancer nurses. International Journal of Nursing Studies 32(3), 301-314.

Gascoigne P., Mason M.D. and Roberts E. (1999) Factors affecting presentation and delay in patients with testicular cancer: Results of a qualitative study. Psycho-Oncology 8(2), 144-154. 
Gurevich M., Bishop S., Bower J., Malka M. and Nyhof-Young J. (2004) (Dis)embodying gender and sexuality in testicular cancer. Social Science and Medicine 58(9), 1567-1607.

Guthrie C. (1999) Nurses' perceptions of sexuality relating to patient care. Journal of Clinical Nursing 8(3), 313-321.

Heidenreich A. and Hofmann R. (1999) Quality of life issues in the treatment of testicular cancer. World Journal of Urology 17(4), 230-238.

Higgins A., Barker P. and Begley C. (2006) Sexuality the challenge to espoused holistic care. International Journal of Nursing Practice 12(6), 345-351.

Higgins A., Barker P. and Begley C. (2008) 'Veiling sexualities': a grounded theory of mental health nurses responses to issues of sexuality. Journal of Advanced Nursing 62(3), 307-317. Higgins A., Sharek, D., Nolan, M., Sheerin, B., Flanagan, P., Slaicuinaite, S., Mc Donnell, S., and Walsh, H. (2011) Mixed methods evaluation of an interdisciplinary sexuality education programme for staff working with people who have an acquired physical disability. Journal of Advanced Nursing 10.1111/j.1365-2648.2012.05959.x.

Higgins, A (2012) All of me: embracing sexuality as a dimension of care in Palliative Care-Mental Health Ed J Cooper and D Cooper. Radcliffe Publishing; London pp 126-146.

Jemal A., Siegel R., Ward E., Murray T., Xu J. and Thun M.J. (2007) Cancer statistics. Cancer Journal for Clinicians 57(1), 43-66.

Jonker-Pool G., Van de Wiel H.B.M., Hoekstra H.J., Sleijfer D.T., Van Driel M.F., Van Basten J.P. and Schraffordt-Koops H. (2001) Sexual functioning after treatment for testicular cancer: Review and meta-analysis of 36 empirical studies between 1975-2000. Archives of Sexual Behaviour 30(1), 55-74. 
Kautz D.D., Dickey C.A. and Stevens M.N. (1990) Using research to identify why nurses do not meet established sexuality nursing care standards. Journal of Nursing Quality Assurance 4(3), 67-69.

Kirby R.S. and Eardley I. (1991) Initial Assessment of Patients with Erectile Dysfunction. In Impotence: Diagnosis and Management of Male Erectile Dysfunction (Kirby R.S., Carson C.C. and Webster G.D., eds), Butterworth Heinemann, Oxford.

Lemieux L., Kaiser S., Pereira J. and Meadows L.M. (2004) Sexuality in palliative care: Patient perspectives. Palliative Medicine 18(7), 630-637.

Lesko L. (1993) Psychiatric aspects of bone marrow transplantation - Part 1: Special issues during pre transplant assessment and hospitalization. Psycho-Oncology 2(3), 161-183.

Lewis S.L. and Bor R. (1994) Nurses knowledge of and attitudes towards sexuality and the relationship of these with nursing practice. Journal of Advanced Nursing 20(2), 251-259.

Matocha L. and Waterhouse J. (1993) Current nursing practice related to sexuality. Research in Nursing and Health 16(5), 371-378.

McKee A.L. and Schover L.R. (2001) Sexuality rehabilitation. CANCER Supplement 92(4), 10081012.

Moore A.M. and Higgins A. (2009) Testicular cancer: Exploring the psychosexual issues British Journal of Nursing 18(19), 1182-1186.

Muir A. (2000) Counseling patients who have sexual difficulties. Professional Nurse 15(11), 723726.

National Cancer Registry of Ireland (2011) Cancer in Ireland 2011: Annual Report of the National Cancer Registry. National Cancer Registry, Cork. 
Nazareth I., Lewin J. and King M. (2001) Sexual dysfunction after treatment for testicular cancer. Journal of Psychosomatic Research 51(6), 735-743.

Reed F. and Fitzgerald L. (2005) The mixed attitudes of nurse's to caring for people with mental illness in a rural general hospital. International Journal of Mental Health Nursing 14(4), 249-257. Robertson J. (2010) CPD: Continuing Professional Development - A message for men. Occupational Health 62(9), 30-33.

Ross C.A. and Goldner E.M. (2009) Stigma, negative attitudes and discrimination towards mental illness within the nursing profession: A review of the literature. Journal of Psychiatric and Mental Health Nursing 16(6), 558-567.

Rudberg L., Carlsson M., Nilsson S. and Wikblad K. (2002) Self-perceived physical, psychologic and general symptoms in survivors of testicular cancer 3 to 13 years after treatment. Cancer Nursing 25(3), 187-195.

Sanden I., Satterlund Larrson U. and Eriksonn C. (2000) An interview study of men discovering testicular cancer. Cancer Nursing 23(4), 304-309.

Shuman N. and Bohachick P. (1987) Nurses' attitudes towards sexual counselling. Dimensions of Critical Care Nursing 6(2), 75-81.

Syse, A; Kravdal, (2007) Does Cancer affect the divorce rate? Demographic reseach 16 469-492

Tsai Y. (2004) Nurses' facilitators and barriers for taking a sexual history in Taiwan. Applied Nursing Research 17(4), 257-264.

Van Basten J.P., Jonker-Pool, G., Van Driel, M.F., Sleijfer, D,Th., Van de Wiel, H.B.M., Mensink, H.J.A., Schraffordt-Koops, H., Hoekstra, H.J. (1996) Fantasies and facts of the testes. British Journal of Urology 78(5), 756-762. 
Van Basten J.P., Van Driel M.F., Hoekstra H.J., Sleijfer D.T., Van de Wiel H.B.M., Drostes H., Schraffordt-Koops H. and Menisk H.J.A. (1999) Objective and subjective effects for testicular cancer on sexual function. British Journal of Urology International 84(6), 671-678.

Van't Spijker A., Trijsburg R.W. and Duivenvoorden H.J. (1997) Psychological sequelae of cancer diagnosis: A meta-analytical review of 58 studies after 1980. Psychosomatic Medicine 59(3), 280-293.

Waterhouse J. and Metcalfe M. (1991) Attitudes toward nurses discussing sexual concerns with patients. Journal of Advanced Nursing 16(9), 1048 - 1054.

Watson C. (1991) Sexual roles in nursing care. Nursing 4(44), 13-14.

Wilson M.E. and Williams H.A. (1988) Oncology nurses' attitudes and behaviors related to sexuality of patients with cancer. Oncology Nursing Forum 15(1), 49-53.

Young E.W. (1984) Patients' plea: Tell us about our sexuality. Journal of Sex Education and Therapy 10, 53-56. 